\title{
EDITORIAL
}

\section{INTERNATIONAL AND COMPARATIVE ADULT EDUCATION}

Internationalisation processes are currently experiencing divergent developments:

On the one hand we can observe several pleas for intensified internationalisation. These pleas are made by politicians from different European countries who turn to internationalisation and/or the European Union (EU) as a means of responding to political demands such as the regulation of the financial market, free trade agreements or migration. But one can also find tendencies in politics which try to establish a distance from international developments and focus on the nation state. The strengthening of very conservative or even extreme right-wing parties in many European countries can be understood as an indicator of these developments.

Looking at internationalisation, we can observe quite different emotions. On the one hand one can find elaborate parts of societies which see the free movement of people and trade as an important value. Internationalisation is understood in this sense as unlimited possibilities, as a source of creativity, as a demand for the advancement of human rights and as personal connections between people around the world. Another part of society is facing internationalisation mainly with fear. They are experiencing developments which demand change in their life contexts. They wonder if they can keep up with these developments and what this means for their living conditions.

Internationalisation can mean release from fixed and close norms, from traditions of the past and consequently empowerment to take one's own decisions about one's life. In consequence, internationalisation asks each person for self-determination in their own life - and is bounded at the same time by the traditions, values and norms of each single person's context. As a consequence, this means that this self-determination can be experienced as a threat and/or excessive demand.

Keeping all these differences in mind, internationalisation is a phenomenon that cannot be stopped, pushed back or encapsulated. Moreover, internationalisation is interwoven with all our lives. Each trip to the supermarket, each news item on television and in Europe even many political decisions are deeply interwoven with internationalisation processes. Anti-globalist movements make several critical perspectives on internationalisation processes visible: human rights, climate issues, financing structure. This calls for responsibility within all these processes. 
International and comparative research in adult education takes place against the background of these divergent developments. It makes visible the need to understand and interpret these developments. In consequence, international comparison means research into these differences instead of final understanding. It means research into the possible ways of understanding and an investigation into an empathic understanding of different perspectives. Consequently, international comparison in adult education means international and comparative adult education that strives

"[...] to understand in a cognitive, emotional, and social way the limitations of our understanding of our own and other phenomena. Ideally, this insight leads to an attitude of further questioning one's own understanding in an ongoing endeavour to working on deeper understanding. An ideal 'result' [...] is to never have a final result, but to continue the never ending journey of personal efforts to try to understand each other. This also means searching for the things that link us to each other: to be aware of the always existing boundaries of our own understanding while developing an attitude of "constantly trying"" (Egetenmeyer, 2016, p. 19).

The Winter School entitled "International and Comparative Adult Education and Lifelong Learning" takes this approach and in 2018 took place for the fifth time at the University of Würzburg. ${ }^{1}$ Between 2015 and 2018 it was funded through the ERASMUS+ Strategic Partnership grant "Comparative Studies in Adult and Lifelong Learning" (COMPALL) ${ }^{2}$. It was organized by the University of Würzburg in collaboration with an extensive partner network of universities with expertise in adult education in Europe: Aarhus University (Denmark), University of Lisbon (Portugal), Helmut Schmidt-University in Hamburg (Germany), University of Florence (Italy), University of Padua (Italy) and University of Pécs (Hungary). Additionally, there were several associated partners that strongly supported the international Winter School. In 2018 these partners were the University of Ljubljana (Slovenia), University of Minho (Portugal), Obafemi Awolowo University in Ile-Ife (Nigeria), International Institute for Adult and Lifelong Learning in New Delhi (India) and University of Delhi (India). All the partners experienced the joint teaching of students from our universities as valuable and a perfect context for doing international comparisons.

Every year, the success of previous Winter Schools brought together in Würzburg up to 90 students and 20 lecturers from around the world. This work has now been awarded with the ERASMUS+ Strategic Partnership grant "International and Comparative Studies for Students and Practitioners in Adult Education and Lifelong Learning" (INTALL) in the 2018-2021 period ${ }^{3}$, in which we welcome the University of Ljubljana und Dublin City University as well as two practitioner associations (European Association for the Education of Adults and DVV International) as new partners in the programme. Bringing

1 For a detailed outline and reflection of the Winter School see Egetenmeyer (2017) and Egetenmeyer, Guimarães and Németh (2017).

2 See https://www.hw.uni-wuerzburg.de/compall/startseite/

3 See https://www.hw.uni-wuerzburg.de/intall/startseite/ 
students and practitioners together to research adult education and lifelong learning means reflecting local adult education practices against the background of international developments. It holds great potential for supporting the empathic understanding of the interdependencies between local and international developments. This is what the INTALL project will develop until 2021. Therefore, it will result in four intellectual outputs: (1) a joint learning methodology (including a Winter School) for students and practitioners; (2) a joint learning community for university and practice teachers in adult and continuing education to connect international teaching and learning settings; (3) a portfolio method to strengthen the employability in adult education and lifelong learning; and (4) a digital learning offer for self-directed online learning.

In 2016, the COMPALL/INTALL-consortium started offering doctoral students guidance on the publication of a comparative paper in joint authorship. The comparison is based on the studies participants work on together with their supervisors as part of comparative group work at the Winter School. There, they take their comparisons and interpretation they are working on during the winter school and improve their research to yield substantial interpretations and comparisons. So far, this process has resulted in three issues published with Peter Lang Publishers (Egetenmeyer, 2016a; Egetenmeyer, Schmidt-Lauff and Boffo, 2017; Egetenmeyer and Fedeli, 2017).

This thematic issue of Studies in Adult Education and Learning/Andragoška spoznanja further contributes to this publishing process using open access. The issue brings together five comparative papers and two book reviews.

All comparative papers are prepared in joined authorship and cover various topical issues in adult education across different contexts, continents, countries, institutions and actors. They focus on mega (policies of international and transnational organisations), macro (national policies), meso (educational institutions, providers) and micro (actors, learners) levels of analysis and their interdependencies, and build the comparison on analysing policy documents and instruments, country reports and strategies, regulations, data reports and statistics, websites and curricula related documents. Some contributions consider fairly similar countries (for instance, Greece and Portugal) and others quite different ones (for example, Denmark and India or Germany and Nigeria) in terms of their history, culture, political system, economy, location and size. All contributions build mainly on a type of "cross-country comparisons in adult education" (Milana, 2017, p. 22), although linked to European or global perspectives in adult education.

In the first paper, Catarina Doutor and Paula Guimarães discuss and compare adult education policies in Greece and Portugal, two semi-peripheral countries in the EU that share more similarities than differences, also, in part, because of the influence of EU guidelines and funding. Based on a critical analysis of adult education policies in both countries, the authors argue that both countries promote adult education as a strategy for modernisation and competitiveness in line with EU guidelines but not any longer in line with adult democratic and emancipatory policies. 
The next paper, prepared by Jelena Stepanova, Tino Concetta and Monica Fedeli, also focuses on two EU countries, namely Italy and Latvia, and analyses and compares students' voice, that is practices of hearing the students' voices as teaching and learning methods, at the University of Padua and the University of Latvia. The authors discuss the factors that determine the differences and similarities between student voice practices in these institutions, focus on the roles and actions of the actors, and argue that both institutions support student participation/engagement in higher education and, in spite of some improvements that are still needed, they are on the right track to implement it on all levels in all dimensions.

In the third paper, prepared by Sabine Schmidt-Lauff, Jörg Schwarz, Adedolapo Femi-Aderinto and Taiwo Olatunji, and the authors discuss changes in temporalities modern societies have been facing and how these changes influence adult education providers, especially through flexibilisation. By comparing well-established and highly recognised adult education and learning centres in Nigeria and Germany, the authors investigate what challenges result for adult education and how adult education providers react in terms of flexibilisation. The authors argue that shifts in temporalities cause similar challenges in both countries and that they appear to be an important driver of flexibilisation in adult education and learning.

In the fourth paper, Shalini Singh and Søren Ehlers explore and compare the development of the recognition of prior learning (RPL) policy in two contrasting contexts, Denmark and India, and analyse what makes RPL policy effective in a given context. By applying Ehlers' Box Model, Integrated Implementation Model and Policy Instruments as a conceptual framework for the analysis of RPL policy, the authors argue that the crucial factors of success for effective policy outcomes are engagement of stakeholders in the policy process, ownership and accountability leading to policy implementation in the short run and policy evolution in the long run, and the use of an appropriate mix of policy instruments that enables the implementation of a certain policy design in a given context.

In the final paper, Carlo Terzaroli and Yinusa Oyekunle analyse models and activities of career services as a measure of supporting student employability in higher education, and compare career services of the University of Florence (Italy) and the University of Lagos (Nigeria) in terms of their impact on student employability. The authors argue that the future perspective for career services in both universities can be found in the close cooperation with stakeholders and that the integration of the employers' point of view, as well as the co-planning of training and matching activities, represents one of the key elements for creating better connections in tertiary education.

The thematic issue is brought to a close by two book reviews from the Winter Schools prepared by Simona Šinko on Adult Education and Work Contexts: International Perspectives and Challenges and Adult Learning and Education in International Contexts: Future Challenges for its Professionalization. 


\section{REFERENCES}

Egetenmeyer, R. (2016). Comparing Adult Education and Lifelong Learning in Europe and beyond: An Introduction. In R. Egetenmeyer (Ed.), Adult and Lifelong Learning in Europe and Beyond. Comparative Perspectives from the 2015 Würzburg Winter School (pp. 13-26). Frankfurt: Peter Lang.

Egetenmeyer, R. (Ed.) (2016a). Adult and Lifelong Learning in Europe and Beyond Comparative Perspectives from the 2015 Würzburg Winter School. Frankfurt: Peter Lang.

Egetenmeyer, R. (2017). The internationalisation of studies in adult education. The Example of COMPALL: Comparative Studies in Adult Education and Lifelong Learning. Studies in Adult Education and Learning/Andragoška spoznanja, 23(4), 121-134.

Egetenmeyer, R., \& Fedeli, M. (Eds.) (2017). Adult Education and Work Contexts: International Perspectives and Challenges. Comparative Perspectives from the 2017 Würzburg Winter School. Frankfurt: Peter Lang.

Egetenmeyer, R., Guimarães, P., \& Németh, B. (Eds.) (2017). Joint Modules and Internationalisation in Higher Education. Reflections on the Joint Module. „Comparative Studies in Adult Education and Lifelong Learning “. Frankfurt: Peter Lang.

Egetenmeyer, R., Schmidt-Lauff, S., \& Boffo, V. (Eds.) (2017). Adult Learning and Education in International Contexts: Future Challenges for its Professionalization. Comparative Perspectives from the 2016 Würzburg Winter School. Frankfurt: Peter Lang.

Milana, M. (2017). Global and Comparative Adult Education Research: A Response to John Field, Klaus Künzel and Michael Schemmann. International Yearbook of Adult Education/Internationales Jahrbuch der Erwachsenenbildung, 40, 13-27. 